\title{
THE MATHEMATICAL MODELING OF THE EPIDEMIC DISEASES INDUCED BY BIOLOGICAL ATTACK WITH CONTAGIOUS AGENTS
}

\author{
Viorel ORDEANU, Ph.D., \\ Col. (ret.) Prof. MD SR, “Titu Maiorescu” University, Bucharest, Romania. \\ E-mail: ordeanu_viorel@yahoo.com \\ Lucia Elena IONESCU, Ph.D., \\ "Cantacuzino" National Military Medical Institute for Research-Development, Bucharest, \\ Romania. E-mail: ionescu.lucia@gmail.com
}

\begin{abstract}
The current security context illustrated by the COVID-19 pandemic shows us that we have vulnerabilities, that there are threats and that there will be risks, including biological ones. In the field of BIO defense it is almost impossible to experiment at the general level. This can only be done on time in the laboratory, in vitro, in vivo and possibly in silico. The calculation methodology for the effects of possible attack with contagious biological warfare agents has certain assumptions and limitations. Considering that the population is homogeneous it results that the isolated groups, to which the infection it does not spread, will show an overestimation. Possible individual variations, particular diseases and asymptomatic cases are not taken into account so either an underestimation or an overestimation occurs. In the mathematical modeling of the epidemic diseases induced by biological attack with contagious agents can use the SEIRP model: Susceptible, Exposed and Infected, Infectious, Removed and Prophylaxis Efficacious Model. The study is important for medical operational planning.
\end{abstract}

Keywords: biological attack; living biological warfare agents; contagious agents; mathematical modeling; probable health losses.

\section{Introduction}

Biological weapons are also called the atomic weapon of the poor due to the possible devastating effect of the attack, through health losses, psychological effect and countermeasures expenditures. To estimate the effect, the probable health losses must be calculated, by mathematical modeling of the epidemic induced by the biological attack with contagious agents. The principles of mathematical epidemiology have been adapted and are also presented in NATO documents, for unitary application in the allied armies.

The calculation methodology for the effects of the attack with contagious biological warfare (WBA) has certain assumptions and limitations for the calculation in cases on contagious agents. The population is considered to be relatively large and unstructured (homogeneous) for a regional or metropolitan epidemic and cannot be extrapolated to geographically separate military units. Considering that the population is homogeneous, it results that in the isolated groups, in which the contagion does not spread, an overestimation appears. For simplicity, possible individual variations, particular diseases and asymptomatic cases are not taken into account, so either an underestimation or an overestimation occurs. This assumption is justified by the complexity of the parameters in infectious diseases, which involve a biunivocal relationship between the pathogen and the host organism, each being influenced by natural and artificial environmental factors. 
The population is considered to be relatively large and unstructured (inhomogeneous) for a regional or metropolitan epidemic and cannot be extrapolated to geographically separate military units. Considering that the population is homogeneous, it results that in the isolated groups, in which the contagion does not spread, an overestimation appears. For simplicity, possible individual variations, particular diseases and asymptomatic cases are not taken into account, so either an underestimation or an overestimation occurs. This assumption is justified by the complexity of the parameters in infectious diseases, which involve a biunivocal relationship between the pathogen and the host organism, each being influenced by natural and artificial environmental factors. The prediction errors in the current Covid-19 pandemic are illustrative in this regard.

For the situation of prophylaxis (by vaccination) or pre-exposure or intra-exposure prophylaxis (with individual and/or collective protective equipment) or post-exposure (with antibiotics or antivirals) the equation differs according to the SEIRP model: susceptible, exposed, infected, outgoing (discharged or deceased) and effective prophylaxis.

The human response to contagious agents incorporates the same set of mathematical submodules as to noncontagious agents: latency (incubation), mortality, disease duration, and disease severity over time (dynamics). These are incorporated in the SEIRP epidemiological model which includes: specificity (agent and disease), susceptibility (population), number of exposed and infected, infection (number of patients), ,removed" namely exited (cured or dead), prophylaxis efficiency, to which are added the specific factors: the rate of transmission ( $R$ factor) and the spread of the contagious disease in the respective population. The dynamics of the epidemic can be presented schematically in the form of an algorithm with cohorts (groups) with evolution over time, from the exposed population to the cured and dead, adapted after Allied Medical Publication-8(C), (AmedP-8(C)), 11-38.

\section{Model of calculation}

The model (for example, US Army SEIRP) uses a set of equations that are solved sequentially daily for each time period $(t)$ greater than or equal to 1 day $(t=1)$, the resulting cohorts being time dependent. The calculation for contagious does not estimate the medical treatment, the number of patients who are saved or the time required, so no specific time is provided for leaving the medical system (it is considered that the survivors remain indefinitely under medical care). This interpretation is medically useful only for certain cases with prolonged evolution, but it is a reality for military actions because it cannot be counted on those soldiers that they can continue the mission, so they will have to be replaced.

\section{General formula is:}

[17] $\mathrm{N} 0=\mathrm{P}(\mathrm{t})+\mathrm{S}(\mathrm{t})+\mathrm{E}(\mathrm{t})+\mathrm{I} 1(\mathrm{t})+\mathrm{I} 2(\mathrm{t})+\mathrm{R}(\mathrm{t})$, where:

$\mathrm{N} 0=$ estimated total number of contagious patients

$\mathrm{P}(\mathrm{t})=$ estimated number of prophylaxis

$\mathrm{S}(\mathrm{t})=$ estimated number of susceptible ill people

$\mathrm{E}(\mathrm{t})=$ estimated number of exposed people

$\mathrm{I} 1(\mathrm{t})=$ estimated number of stage 1 contagious patients

$\mathrm{I} 2(\mathrm{t})=$ estimated number of stage 2 contagious patients

$\mathrm{R}(\mathrm{t})=$ estimated number of exited (cured or dead)

The equations embedded in the SEIRP methodology use a set of parameters as input data:

$\alpha=$ probabilitaty that people with stage 1 disease will infect susceptible people

$\rho \mathrm{S}=$ efficacy of prophylaxis in the susceptible cohort

$\rho \mathrm{E}=$ efficacy of prophylaxis in the exposed and infected cohort

$\mu \mathrm{E}=$ period of time when individuals were in the cohort of exposed and infected

$\mu 1=$ period of time when individuals were in the cohort of stage 1 contagious patients

$\mu 2=$ period of time when individuals were in the cohort of stage 2 contagious patients

$\beta(\mathrm{t})=$ rate of disease transmission over time 
$\operatorname{von}(t)=$ binary prophylaxis parameter (if prophylaxis was applied: Yes $=1$ şi $\mathrm{No}=0$ )

$\operatorname{voff}(\mathrm{t})=$ binary prophylaxis parameter (if prophylaxis is discontinuous: discontinuous $=1$ and continuous $=0$ )

$\operatorname{pf}(\operatorname{dn})=$ the probability of death, which in infectious agents is dose-independent, therefore:

[18] $\operatorname{pf}(\mathrm{dn})=\mathrm{pf}$

The initial number for which prophylaxis is effective in group $\mathrm{n}$, if all individuals in have received prophylaxis, is:

[19] $\operatorname{Pn}(0)=\hat{i n} \times \rho, \quad$ where:

$\operatorname{Pn}(0)=$ the initial number of individuals in the group in whom prophylaxis is effective.

The infectivity submodel is calculated only if the prophylaxis is not effective, so the initial number of exposed, infected and patients in stage 1:

[20] $\operatorname{En}(0)=\mathrm{E} 1 \mathrm{n}(0)=($ in $\times(1-\rho) \times \operatorname{PE}(\mathrm{dn}), \quad$ where:

$\operatorname{En}(0)=$ initial number of exposed and infected people in group $n$

$\mathrm{E} 1 \mathrm{n}(0)=$ the initial number of exposed and infected stage 1 patients in group $\mathrm{n}$

The total number of individuals in whom prophylaxis is effective $\mathrm{P}(0)$ and the total number of individuals who have been exposed and infected $\mathrm{E}(0)$ is the sum of those in each group:

[21] $\mathrm{P}(0)=\Sigma \operatorname{Pn}(0)=\rho \Sigma \mathrm{In}$ $\mathrm{n}=1 \quad \mathrm{n}=1$ $\mathrm{N} \quad \mathrm{N}$

[22]

$$
\mathrm{E}(0)=\Sigma \mathrm{E} 1 \mathrm{n}(0)=(1-\rho) \sum(\mathrm{in} \times \mathrm{PE}(\mathrm{dn}))
$$

$\mathrm{P}(0)$ and $\mathrm{E}(0)$ values are input data for SEIRP. The individual progression for exposed and infected and patients stage 1 (E1n) to stage 2 (E2n) after the minimum incubation period is: $\mathrm{E} 2 \mathrm{n}(0)=0$. We assume that initially there were no patients or evacuees, meaning $\mathrm{I}(0)=0$ and $\mathrm{I} 2(0)=0$ and $\mathrm{R}(0)=0$, the susceptible population is:

[23] $\quad \mathrm{S}(0)=\mathrm{N} 0-\mathrm{P}(0)-\mathrm{E}(0)$

If each of these parameters is known, the equation is solved sequentially. The calculation stops at time $\mathrm{t}=$ the day when the transmission factor tends to zero, plus the time of manifestation of the disease, meaning:

[24] $\quad \mu \mathrm{E} 1+\mu \mathrm{E} 2+\mu 1+\mu 2$

Number of people for whom the prophylaxis is efficient:

[25] $\mathrm{P}(\mathrm{t})=\mathrm{P}(\mathrm{t}-1)+\rho \mathrm{S} \times$ von $(\mathrm{t}-1) \times \mathrm{S}(\mathrm{t}-1)+\rho \mathrm{E} \times$ von $(\mathrm{t}-1) \times \mathrm{E}(\mathrm{t}-1)-$ voff $(\mathrm{t}-1) \times \mathrm{P}(\mathrm{t}-1)$

Number of susceptible people in $t$ moment:

[26] $\quad \underline{\mathrm{S}(\mathrm{t})=\mathrm{S}(\mathrm{t}-1)-\beta(\mathrm{t}-1) \times \mathrm{S}(\mathrm{t}-1) \times[\dot{\alpha} \times \mathrm{I} 1(\mathrm{t}-1)+(1-\alpha) \times \mathrm{I} 2(\mathrm{t}-1)] \Delta \mathrm{t}}$

Number of exposed and infected people in a given moment:

[27] $\quad \mathrm{E}(\mathrm{t})=\mathrm{E} 1(\mathrm{t})+\mathrm{E} 2(\mathrm{t})$

From whom in stage 1 , for time $\mathrm{t} \leq$ minimum time of incubation:

[28] $\quad \mathrm{E} 1(\mathrm{t})=\mathrm{E} 1(\mathrm{t}-1)$

And for time $\mathrm{t}>$ minimum time of incubation:

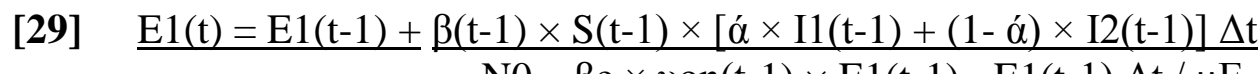

$$
\mathrm{N} 0-\beta \mathrm{e} \times \operatorname{von}(\mathrm{t}-1) \times \mathrm{E} 1(\mathrm{t}-1)-\mathrm{E} 1(\mathrm{t}-1) \Delta \mathrm{t} / \mu \mathrm{E}
$$

For the calculation of the number of exposed and infected stage 2 , the minimum incubation time, $\mathrm{t}$ min, is also considered:

$\begin{array}{lll}{[30]} & \text { for } \mathrm{t}<\mathrm{tmin} & \mathrm{E} 2(\mathrm{t})=0 \\ {[\mathbf{3 1}]} & \text { for } \mathrm{t}=\mathrm{tmin} & \mathrm{E} 2(\mathrm{t})=\mathrm{E} 1(\mathrm{t}-1) \\ {[\mathbf{3 2}]} & \text { for } \mathrm{t}>\mathrm{tmin} & \frac{\mathrm{E} 2(\mathrm{t})=\mathrm{E} 2(\mathrm{t}-1)+\mathrm{E} 2(\mathrm{t}-1) \Delta \mathrm{t}}{\mu \mathrm{E} 1-\mathrm{E} 2(\mathrm{t}-1) \Delta \mathrm{t} / \mu \mathrm{E} 2}\end{array}$


For the number of patients in stage 1 at time $t$ :

[33] $\quad \underline{\mathrm{I} 1(\mathrm{t})=\mathrm{I} 1(\mathrm{t}-1)+\mathrm{E} 2(\mathrm{t}-1) \Delta \mathrm{t}}$

$$
\mu \mathrm{E} 2-\mathrm{I} 1(\mathrm{t}-1) / \mu 1
$$

and for the number of patients in stage 2 at time $t$ :

[34] $\underline{\mathrm{I} 2(\mathrm{t})=\mathrm{I} 2(\mathrm{t}-1)+\mathrm{I} 1(\mathrm{t}-1) \Delta \mathrm{t}}$

$\mu 1-\mathrm{I} 2(\mathrm{t}-1) \Delta \mathrm{t} / \mu 2$

Number of exited people (cured or deceased) at time t:

[35] $\quad \mathrm{R}(\mathrm{t})=\mathrm{R}(\mathrm{t}-1)+\mathrm{I} 2(\mathrm{t}-1) \Delta \mathrm{t} / \mu 2$

Number of deaths:

[36] $\quad \operatorname{Rf}(\mathrm{t})=\mathrm{pf} \times \mathrm{R}(\mathrm{t})$

Number of patients remaining in the medical system:

[37] $R m(t)=R(t)-R f(t)$

The methodology for calculating the human response to contagious agents is supplemented by the calculation for new cases and new deaths. The estimation of diseases with contagious biological agents, at a given moment, is calculated on cohorts: population at risk $\mathrm{P}(\mathrm{t})$, exposed $\mathrm{E}(\mathrm{t})$, patients stage 1 - I1 $(\mathrm{t})$, patients stage 2 - I2(t), hospitalized $\mathrm{Rm}(\mathrm{t})$, deaths $\operatorname{Rf}(\mathrm{t})$, number of new cases per day - I1 new $(\mathrm{t})$ and $\mathrm{I} 2$ new $(\mathrm{t})$, new deaths per day Rf new $(\mathrm{t})$. The estimate of the number of wounded/sick in battle is calculated according to the level of severity of the disease at each stage and differs according to the biological agent/disease. It is calculated the total number and new cases per stage, namely WIA I1 new $(\mathrm{t})$ and I2 new $(\mathrm{t})$.

Number of new cases in stage 1 at time t:

[38] I1 new $(\mathrm{t})=\mathrm{E} 2(\mathrm{t}-1) \Delta \mathrm{t} / \mu 2$

Number of new cases in stage 2 at time t:

[39] $\mathrm{I} 2 \operatorname{new}(\mathrm{t})=\mathrm{I} 1(\mathrm{t}-1) \Delta \mathrm{t} / \mu 1 \quad$ where:

I1 new $(\mathrm{t})=$ number of infected people who become stage 1 in time period $\mathrm{t}$, and $\mathrm{I} 2$ new $(\mathrm{t})=$ number of infected people who get stage 2 disease in time period $\mathrm{t}$.

Number of new deaths at time $t$ :

[40] $\quad \operatorname{Rf} \operatorname{new}(\mathrm{t})=\mathrm{pf} \times(\mathrm{I} 2(\mathrm{t}-1) \Delta \mathrm{t} / \mu 2$

where:

Rf new $(\mathrm{t})=$ number of dead people in the period of time $\mathrm{t}$.

From these data we calculate WIA and DOW taking into consideration the time, after the incubation period, in the form of a specific algorithm, (AmedP-8(C)), after which we adapted estimation examples for health losses caused by the most contagious WBA likely to be used in an attack (Allied Medical Publication-8(C), 223-227).

\section{Estimation of plague cases}

Plague (pestis) is a very serious infectious-contagious disease caused by the cocobacillus Yersinia pestis that can cause bubonic plague (with lymph node infection), lung plague or both. The methodology considers only the aerosolization variant, because it is the most efficient from a military point of view, compared to the classic methods of vector distribution (sick rats or infected fleas). The disease can be treated with antibiotics both curatively and prophylactically after exposure. There is a vaccine for prophylaxis and if available it protects against disease or reduces the severity of the disease, but the lung form has a very high mortality. However, this vaccination incapacitates the military for hours or days. (Allied Medical Publication-8(C), 228)

Infectivity: the probability of plague disease is modeled by the log-probit function with 1 probit/log dose at the value of 20,000 CFU, but with very high variability. (Allied Medical Publication-8(C), 229-231) 
The mathematical function of cumulative distribution is with lognormal distribution

[41] PE pestis $(\operatorname{dn})=1 / 2+1 / 2\{\operatorname{erf}(\underline{\ln (\operatorname{dn})-\mu})\}$

$$
\sigma \sqrt{2} \quad \text { where: }
$$

$\mathrm{n}=$ number of groups

PE pestis $(\mathrm{dn})=$ number of people exposed to the dose of plague in group $\mathrm{n}$ who will get sick (exposed and infected)

Dn $=$ pestis dose (UFC) in group $n$

$\mu=$ natural variable of logarithm of infectious dose $50 \%$

$\ln ($ DI50) $=$ in $(66$ UFC $)=4.1897$

$\mathrm{m}=$ probit $(1$ probit/log dose $) \quad 1 / \mathrm{m} \quad 1 / 1$

$\sigma=$ standard deviation of natural logarithm variable $\mathrm{e}=\mathrm{e} \quad=2.7193$

erf $=$ error of function

$$
\operatorname{erf}(x)=\frac{2}{\sqrt{\pi}} \int_{0}^{\mathrm{x}} \mathrm{e}^{-\mathrm{t} 2} \mathrm{dt}
$$

Lethality is considered in untreated pneumonic plague to be practically $100 \%$, so the probability of death is: $\mathrm{pf}=1$.

Recommended parameters for plague epidemiology according to AMedP- $8(\mathrm{C})$ table A47:

$\mu \mathrm{E} 1=1$ day

$\mu \mathrm{E} 2=3.3$ days

$\mu 1=1$ day in stage 1 , with severity level 2

$\mu 2=1.5$ days in stage 2 , with severity level 4

$\Delta \mathrm{t}=1$ day

$\alpha=0$

$\mathrm{P}=\mathrm{N} / \mathrm{A}$ (variable)

$\mathrm{PS}=0.95$

$\mathrm{PE}=0.95$

$\operatorname{von}(t)=1$ for $t=0$ days and 0 for $1 \neq 0$ days

$\operatorname{voff}(\mathrm{t})=1$ for $\mathrm{t}=7$ days and 0 for $1 \neq 7$ days

Secondary $(\beta)$ transmission rate of plague according to historical epidemics: days 1 and 2 transmission 0, days 3-17 high transmission, days 18-32 low transmission, day 33 very low and after 33 days $=0$. From this model transmission started the quarantine isolation method (quaranta - 40 days in Italian) during the plague pandemic.

Model parameters for estimating plague cases. Infectivity and lethality sub-models in plague patients are incorporated into the SEIRP model. The disease profile is unique to nonsurvivors, with a period of symptoms characteristic of lung infection and two stages of the disease, so there is no other disease profile because mortality is $100 \%$. Disease profile for deceased plague patients is shown in Table 1, adapted from AmedP-8(C), 234.

Table no.1: Disease profile for plague deaths

\begin{tabular}{|c|c|c|}
\hline Criteria & Stage 1 & Stage 2 \\
\hline Signs and symptoms & Fever & Fever \\
& Headache & Dyspnoea \\
& Nausea & Dry cough that becomes productive \\
& Vomiting & Bloody sputum \\
& Vertigo & Cyanosis \\
& Tachypnea & Illness \\
\hline
\end{tabular}




\begin{tabular}{|c|c|c|}
\hline Criteria & Stage 1 & Stage 2 \\
\hline & $\begin{array}{l}\text { Tachycardia } \\
\text { Dry cough }\end{array}$ & $\begin{array}{c}\text { Delirium } \\
\text { Ataxia } \\
\text { Confusion } \\
\text { Disorientation } \\
\text { Apathy } \\
\text { Coma } \\
\text { Collapse } \\
\text { Respiratory arrest }\end{array}$ \\
\hline Severity & 2 (moderate) & 4 (very severe) \\
\hline Treatment & $\begin{array}{l}\text { If untreated it } \\
\text { goes to stage } 2 \text {, } \\
\text { if the right } \\
\text { treatment is } \\
\text { started it can } \\
\text { stop going to } \\
\text { stage } 2\end{array}$ & Even if treatment is started, the patient dies \\
\hline
\end{tabular}

It should be noted that throughout history, plague epidemics have been the most lethal infectious diseases.

Antibiotic prophylaxis is recommended immediately after exposure to pestis aerosols, ciprofloxacin, other fluoroquinolones or other oral antibiotics or within a maximum of 24 hours and may reduce mortality by $95 \%$. Treatment can also be done with injectable Streptomycin for 10 days (AmedP-8(C), 236).

\section{Estimation of smallpox cases}

Smallpox is a serious viral disease with high mortality but preventable by vaccination. In 1980 it was declared by the WHO as eradicated, being the first infectious-contagious disease to disappear as a result of modern medicine. Since then, there has been no vaccine and no smallpox vaccination. If an aggressor uses smallpox virus for biological attack, the consequences could be catastrophic because the younger generations are not vaccinated and the resumption of vaccine production takes a long time. The virus spreads through the air and through contact, causes specific damage to the skin and mucous membranes and if inhaled destroys the lungs and the disease is fatal.

Smallpox parameters. Infectivity is $100 \%$ but the disease is triggered only if the dose is sufficient, over 10 UFP (units forming plates), otherwise the probability of infection is 0 .

PE smallpox $(\mathrm{dn})=1$ for $\mathrm{dn} \geq 10$ UFP and

PE smallpox $(\mathrm{dn})=0$ for $\mathrm{dn}<10 \mathrm{UFP}$

Lethality is dependent on immunity, respectively on vaccine status: $30 \%$ in unvaccinated and $3 \%$ in vaccinated prophylactically or immediately after exposure, the others exposed and infected will get the disease and be cured he model parameters for the evolution of smallpox cases are presented in Tables 2 and 3 (adaptation according to AmedP-8(C). (Allied Medical Publication-8(C), 240).

Table no. 2: Smallpox model parameters for comparing survivors/non-survivors, with and without vaccination

\begin{tabular}{|l|l|l|}
\hline \multicolumn{1}{|c|}{ Parameter } & \multicolumn{1}{|c|}{ Survivors } & \multicolumn{1}{c|}{ Non-survivors } \\
\hline$\mu \mathrm{E} 1$ & 7 days & 7 days \\
\hline$\mu \mathrm{E} 2$ & 4.6 days & 4.6 days \\
\hline$\mu 1$ & 2.8 days(stage 1, severity level 2) & 2,8 days (stage 1, severity level 2) \\
\hline
\end{tabular}


STRATEGIES XXI International Scientific Conference

The Complex and Dynamic Nature of the Security Environment

\begin{tabular}{|c|c|c|}
\hline Parameter & Survivors & Non-survivors \\
\hline$\mu 2$ & 12.6 days (stage 2, severity level 3 ) & 12.6 days (stage 2, severity level 4 ) \\
\hline$\mu 3$ & 4 days (stage 3 , severity level 1 ) & N/A! \\
\hline$\Delta \mathrm{t}$ & 1 day & 1 day \\
\hline$\dot{\alpha}$ & 0 & 0 \\
\hline $\bar{P}$ & $0.95 / \mathrm{N} / \mathrm{A}$ & $0.95 / \mathrm{N} / \mathrm{A}$ \\
\hline PS & N/A / 0,95 & N/A / 0.95 \\
\hline $\mathrm{PE}$ & N/A / 0,85 & N/A / 0.85 \\
\hline von $(\mathrm{t})$ & $\begin{array}{l}\text { N/A } / 1 \text { for } \mathrm{t}=1 \text { day } \\
\text { and } 0 \text { pentru } \mathrm{t}>1 \text { day }\end{array}$ & $\begin{array}{l}\text { N/A } / 1 \text { for } t=1 \text { day } \\
\text { and } 0 \text { for } t>1 \text { day }\end{array}$ \\
\hline voff $(\mathrm{t})$ & N/A / 0 & N/A / 0 \\
\hline
\end{tabular}

Secondary transmission of smallpox, according to historical epidemiological data, mainly after the smallpox epidemic in the former Yugoslavia in 1972, shows a specific evolution. In the first 8 days it is not transmitted, in days 9-11 the transmission is moderate, in days 12-20 it is high, it decreases in days 21-28, then it increases again in days 29-37, it returns to moderate transmission in days 38-59, and from day 60 it is no longer transmitted.

The smallpox virus is no longer in nature, the disease has been eradicated for four decades, so a smallpox attack would be incriminating for the aggressor. The only officially and legally stored strains of smallpox virus are in the United States, Russia and the United Kingdom, but there may be others illegally kept by states or non-state organizations. The consequences of the biological attack with smallpox depend on the parameters of the presented submodels. The profile of the disease is different for surviving and non-surviving smallpox patients. For survivors the symptomatic period is divided into 3 stages, and for non-survivors into 2 stages with different signs and symptoms. The usual smallpox profile is shown in Table 9, comparing for survivors and non-survivors (Allied Medical Publication-8(C), 248).

Table no. 3: Comparison of the evolution of smallpox patients

\begin{tabular}{|c|c|c|}
\hline Signs and symptoms & Survivors & Non-survivors \\
\hline $\begin{array}{l}\text { Stage 1 } \\
\text { Severitay level } 2 \\
\text { (moderate), evolution to } \\
\text { stage } 2\end{array}$ & $\begin{array}{l}\text { Fever } 38-40.5^{\circ} \mathrm{C} \\
\text { Illness } \\
\text { Vomiting } \\
\text { Chills } \\
\text { Headache } \\
\text { Back pain } \\
\text { Abdominal pain } \\
\text { Raving }\end{array}$ & $\begin{array}{l}\text { Fever } 38-40.5^{\circ} \mathrm{C} \\
\text { Illness } \\
\text { Vomiting } \\
\text { Chills } \\
\text { Headache } \\
\text { Back pain } \\
\text { Abdominal pain } \\
\text { Raving }\end{array}$ \\
\hline $\begin{array}{l}\text { Stage } 2 \\
\text { Severity level } 3 \text { (severe) } \\
\text { evolution to stage } 3 \text { (if } \\
\text { survives) }\end{array}$ & $\begin{array}{l}\text { Fluctuating fever (decreases but with } \\
\text { peaks at } 40^{\circ} \mathrm{C} \text { ) } \\
\text { Sore throat, dysphagia } \\
\text { Exantem pharyngeal } \\
\text { Maculo-papular rash on the face, } \\
\text { mouth, pharynx, hands, forearms } \\
\text { Maculo-papular rash on the lower } \\
\text { limbs } \\
\text { After a few days: Blisters that turn } \\
\text { into pustules }\end{array}$ & $\begin{array}{l}\text { Fluctuating fever (decreases but with peaks } \\
\text { at } 40^{\circ} \mathrm{C} \text { ) } \\
\text { Sore throat, dysphagia } \\
\text { Exantem pharyngeal } \\
\text { Maculo-papular rash on the face, mouth, } \\
\text { pharynx, hands, forearms } \\
\text { Maculo-papular rash on the lower limbs } \\
\text { After a few days: Blisters that turn into } \\
\text { pustules, leave scars } \\
\text { Severe toxemia, with multiple organ failure } \\
\text { Death }\end{array}$ \\
\hline $\begin{array}{l}\text { Stage } 3 \\
\text { Individual will likely } \\
\text { recover from illness }\end{array}$ & $\begin{array}{l}\text { The general condition is improving } \\
\text { The pustules form crusts, which } \\
\text { when removed leave depigmented } \\
\text { depressions after healing }\end{array}$ & \\
\hline
\end{tabular}


Scenario characterization: attack with aerosols with biological cloud with very high concentration (approx. 1 million PFU/min $/ \mathrm{m}^{3}$ ) in the central area and peripheral decrease, and after passing the cloud the concentration tends to zero. The model is valid for any other lethal virus with high contagiousness: Ebola, Marburg, influenza, coronaviruses (SARS, MERS, SARS-CoV-2) etc.

The exposure medium is considered for accumulation for $10 \mathrm{~min}$, and the dose is influenced by local factors, inhalation (respiration rate $=$ volume of inhaled air per minute) depending on the activity (physical effort). Shelter in buildings or vehicles reduces the absorbed dose (SF vent $\mu$ ) depending on ventilation.

Physical protection (PFn) consists of personal CBRN protective equipment (mainly gas mask) and collective protection in buildings or vehicles equipped with filter ventilation. US Army standards provide a protection factor of $1 / 1667$ for masks and $1 / 3000$ for filter ventilation systems, which should provide very good protection against CBR agents. The calculation of the dose must take into account all these factors, and the calculation of prophylaxis and infectivity, in groups, takes into account pre-exposure prophylaxis by vaccination.

The example shown with smallpox virus does not present the most dangerous situation because there is an effective smallpox vaccine, which the Cantacuzino Institute also manufactured industrially before the cessation of production and if necessary could have resumed its manufacture. But for other contagious viruses, possibly to be used as biological weapons, there are still no vaccines: hemorrhagic fevers, encephalitic fevers, etc. It turns out that the effect of the attack would be very high (very good cost/benefit ratio) but also the risk of pandemic would be so high that the medical risk/benefit implications would be at an unacceptable level. The current COVID-19 epidemic/pandemic is like an unwanted situational experiment, in which we are confronted with a biological agent only partially known and against which we are still experiencing specific medical countermeasures (Viorel ORDEANU, Lucia Elena IONESCU, 2020, 48-61).

\section{Limitations of mathematical modelling in epidemiology}

Contagious viral biological agents are extremely dangerous because antiviral drugs are less effective than antibiotics in bacterial agents, and for many viruses there is no recommended treatment, namely etiological and specific. This does not mean that the respective patients will not be treated, but all appropriate pharmacological and non-pharmacological means will be applied as a non-specific treatment: symptomatic, adjuvant, complementary, off label, etc. to try to heal the patient. Contagious biological agents have the highest degree of efficiency in biological warfare but also an unacceptable level of risk. The only logical solution is the real and definitive renunciation of biological weapons/agents and the exact application of the provisions of the Geneva Convention on the Prohibition of Biological and Toxin Weapons, 1972, (URL: https://www.un.org/disarmament/biological-weapons).

The classic model for contagious bacteria is plague, a zooanthroponotic disease known since Antiquity, which has caused the deadliest known natural epidemics and pandemics in history, but today many countries have vaccine and antibiotic therapy. According to the plague model, the effects of other contagious bacterial diseases can be calculated, usable for biological attacks.

The model for contagious viruses is smallpox, a human-specific disease also known in Antiquity, which in endemic and epidemic form has also caused many deaths, but has been eradicated including by mass vaccination for almost two centuries. The smallpox model can be applied to any other contagious viral agent, but we do not have the recommended vaccine and/or treatment for all of them. It follows that the serious situation presented in this example could be even worse if those viral agents are used. A much worse situation would be if hybrid viruses 
STRATEGIES XXI International Scientific Conference

The Complex and Dynamic Nature of the Security Environment

(for example, Ebola-smallpox) or new synthesized viruses in the laboratory are used, about which almost nothing is known. It is necessary to completely abandon the biological agents of war and bioterrorism, first of all the contagious ones that can be a major danger to humanity.

The calculation examples presented for the effect of the attack with contagious biological agents are extracted and adapted from the NATO specialized literature, for the use of military planners (medical and non-medical) in the situation of biological warfare. They seem very scientific, are based on historical medical experience and are processed with appropriate mathematical formulas. But the reality shown by the current Covid-19 pandemic, seen as a situational experiment, shows that everything is relative and the value of the estimates is only indicative, the theory does not always match the practice.

The Covid-19 pandemic has led to a huge number of new works, which double every two weeks. Many of these papers are first published on preprint servers without undergoing the peer review process, which raises questions about the quality of many of them. This multitude of scientific and pseudo-scientific information compromises the mathematical modeling of the epidemic, and the medical and non-medical countermeasures are chaotic and ineffective, as can be seen in the evolution of the current pandemic. A start-up company says its platform - called Scite.ai - can automatically inform readers if the work has been supported or contradicted by scientific research. By May 2020, the platform had analyzed over 16 million full-text scientific articles from publishers such as BMJ Publishing Group in London and Karger in Basle, Switzerland. However, Jodi Schneider, from the University of Illinois at Urbana-Champaign, says the platform has its limitations related to the literature it has access to and machine learning algorithms. At this time, the Scite.ai analysis of the Covid-19 database is not fully automated, so there is sometimes a delay in how quickly preprints are analyzed by the tool. Scite.ai has about 1,000 visitors per day and approx. 2,700 registered users, the number has been increasing since the site started asking users to register to view the full citation analysis for a given paper (Roxanne Khamsi, 2020). Today, the number of citations of a paper is considered by researchers as a measure of its degree of influence. However, even if a paper is highly cited, it does not mean that it is a reference, says Elizabeth Suelzer, a librarian at the Medical College of Wisconsin Libraries in Milwaukee. For example, the famous study withdrawn in 1998 by former doctor Andrew Wakefield, who claimed that there is a link between autism and vaccines. It is extremely quoted, but most of these quotes are negative. In such situations a tool like Scite.ai could be very helpful.

Josh Nicholson, co-founder and CEO of Scite.ai, first recognized the need for such an instrument in 2012 during his doctorate in cell biology at Virginia Polytechnic Institute and Blacksburg State University when he read a commentary on Nature intensely disputed on scientific reproducibility. In it, a researcher at the biotechnology company Amgen in Thousand Oaks, California, revealed that scientists there could not reproduce the results of 47 of the 53 "reference" studies on cancer. This encouraged Nicholson and biologist Yuri Lazebnik to propose a new citation method to indicate whether a particular study or its findings were verified in subsequent reports. Thus, the two researchers launched Scite.ai in April 2020. The algorithm extracts the text of articles from partner publishers (for example, Rockefeller University Press in New York City and Wiley in Hoboken, New Jersey), and after analysis, eight out of ten papers reported by the tool as supporting or contradicting a study are relatively correctly classified, according to the founder. (Khamsi, Nature, 2020).

Following the same idea, computer simulation programs and algorithms for estimating the evolution of epidemics/pandemics such as Covid-19, are required to be made public to verify their reproducibility. The discussions are extremely heated because most of those who write such programs do not agree. 
Epidemiologist Neil Ferguson, who led the simulation of the coronavirus pandemic at Imperial College London, presented basic estimates of the impact of the pandemic at a private meeting of the UK's leading emergency advisory group at a meeting on 27 February 2020. His figures showed estimates of half a million deaths if nothing is done to stop the virus and modeled how various political interventions could help. The politicized debate over this code demonstrates why scientists may still be reluctant to openly launch the code behind their work. Ferguson - who did not comment on the criticism at the time - agrees that the simulation did not use current methods of coding best practices because it had to be adapted from a model created more than a decade ago to simulate a flu pandemic. He said "There was no time to generate new simulations of the same complexity from scratch," he says, but the team used more modern coding approaches in its other work. However, "none of the criticisms of the code affect math or simulation science" (Chawla, Nature, 2020).

\section{Experimentation in silico - constructive simulation}

Experimentation using constructive simulation is a viable and efficient tool, but insufficiently known and used. At national level, this perspective was mentioned in the Modeling and Simulation Strategy $(M \& S)$ in the Romanian Armed Forces, for the period 2014 $-2024$.

In the Military Strategy of Romania (2021), among the defense capabilities and the priorities of their realization is the development, at joint level, of the national military training capacity through simulation, but also the development of operational medical capabilities and strengthening the medical system of the Ministry of National Defense. (https://sg.mapn.ro/app/webroot/files/project/Strategia\%20militara\%20a\%20Romaniei \% 202.pdf)

The current security context (the Covid-19 pandemic) shows us that we have vulnerabilities, that there are threats and that there will be risks, including biological ones. We must be aware that it would be good to be able to counter them before they materialize, during and especially after, in order to liquidate the consequences.

However, the theoretical conception must be validated by practice. In the field of BIO defense it is almost impossible to experiment at a general level. This can only be done from case to case, in the laboratory, in vitro, in vivo and possibly in silico. Therefore, in the period 2013-2017, in the former Medical-Military Scientific Research Center (MMRC) institutionally taken over by the "Cantacuzino" Institute were conducted constructive simulation experiments in collaboration with the Center for War Games and Doctrinal Experimentation which were basic tools in a project of medical-military scientific research for the optimization and implementation of countermeasures of the bioterrorist attack with non-contagious biological agents, in accordance with NATO/EU standards and compatible with the capabilities of the Alliance.

These experiments are unique in the Romanian Armed Force, and the research results were used for the education and training of military personnel and students of the MedicalMilitary Institute.

The activity can be useful for for understanding and solving complex situations in the field of military medicine and CBRN protection, with the advantage that the benefits can be obtained at extremely low costs. It could also be used as a model for constructive simulation exercises for biological attack with contagious biological warfare agents.

Constructive simulation uses Models and simulations in which simulated people operate simulated systems and real people provide the inputs for this type of simulations, but are not involved in determining the outputs of the simulation process. (Viorel Ordeanu, Manuel DOGARU, Lucia Ionescu, 2015, 103-109). 
The development process of the common synthetic operational environment, necessary for modeling and simulation, uses pre-built or built databases, generated by the dedicated software applications detailed in the exercise plans made by its director and the evaluating director. The results are useful for military and medical-military education as well as for estimating in advance the consequences of a biological attack.

\section{Conclusions}

Biological attack with contagious biological agents can be devastating both through the direct effect and through the infectious-contagious disease that can spread as an epidemic or pandemic and get out of control.

In the mathematical modeling of epidemic diseases induced by the biological attack with contagious agents, the SEIRP model can be used, the calculation methodology having however called assumptions and limitations.

The approach from this point of view is important for operational medical planning and for medical countermeasures, being an important element in the decision-making process regarding the planning of the operation.

\section{BIBLIOGRAPHY:}

***, Coronavirus in context: Scite.ai tracks positive and negative citations for COVID-19 literature, doi: https://doi.org/10.1038/d41586-020-01324-6)

***, Geneva Convention on the Prohibition of Biological and Toxin Weapons (BTWC 1972). (https://www.un.org/disarmament/biological-weapons).

CHAWLA, Dalmeet Singh. 2020. „Critiqued coronavirus simulation gets thumbs up from code-checking efforts". Nature. 08 June 2020. Accessed 29.09.2021. https://www.nature.com/articles/d41586-020-01685-y

https://sg.mapn.ro/app/webroot/files/project/Strategia\%20militara\%20a\%20Romaniei\% 202.pdf

KHAMSI, Roxanne. 2020. „CORONAVIRUS in context: Scite.ai tracks positive and negative citations for COVID-19 literature". Nature. 01 May 2020. Accessed 29.09.2021. https://www.nature.com/articles/d41586-020-01324-6

ORDEANU, Viorel, IONESCU Lucia Elena. 2020. STRATEGIES XXI International Scientific Conference, The Complex and Dynamic Nature of the Security Environment, "The impact of the COVID-19 pandemic on national and international security".

ORDEANU, Viorel, DOGARU, Manuel, IONESCU Lucia. 2015. Buletinul Universităţii Naţionale de Apărare „Carol I”. "Experimental informatical model for defence exercises against biological weapons and bioterrorism".

Technical Reference Manual: NATO Planning Guide for the Estimation of Chemical, Biological, Radiological, and Nuclear (CBRN) Casualties, Allied Medical Publication8(C), (AmedP-8(C)), 11-38, 36 